\title{
Sífilis congénita: presentación como shock séptico después del período neonatal
}

\author{
Daniela Arriagada, Alejandro Donoso, Pablo Cruces y Franco Díaz
}

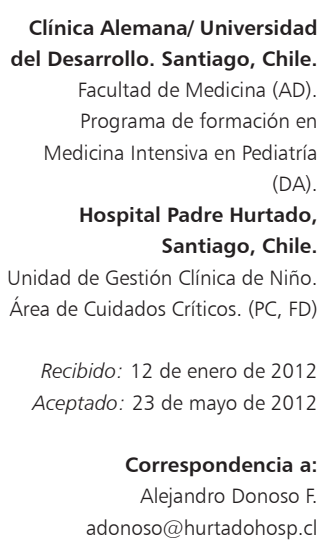

Clínica Alemana/ Universidad

Facultad de Medicina (AD).

Programa de formación en

(DA) \section{西}

a
egaly and perioral, palmoplantar erythematous desquamative scaly lesions. Laboratory data revealed anemia, leukocytosis, thrombocytopenia and C-reactive protein of $183 \mathrm{mg} / \mathrm{l}$. Soon after admission she developed septic shock with leukocytosis up to $45,800 / \mathrm{mm} 3$ and exacerbation of thrombocytopenia, hypoalbuminemia and metabolic acidosis. Congenital syphilis was diagnosed at the second day of admission with VDRL titers of 1:128 in serum and 1:8 in cerebrospinal fluid. Maternal serum VDRL was positive with titers of 1:32. The patient was treated with penicillin for three weeks with adequate clinical and laboratory response. Congenital syphilis is a life threating infection, but cannot always be diagnosed at birth. Health care workers must be aware of the difficulties in obtaining a definitive diagnosis and must have a high index of suspicion, considering the possible errors of prenatal serology and the diverse possible clinical presentations, including neonatal sepsis during the first month of life.

Key words: Syphilis, congenital syphilis, sepsis, pediatrics.

Palabras clave: Sífilis, sífilis congénita, sepsis, pediatría.

\section{Introducción}

\section{L}

a sífilis congénita es una de las infecciones más antiguas de las cuales se tiene conocimiento, existiendo reportes desde el siglo $\mathrm{XV}^{1,2}$. Puede causar graves efectos en el feto en las distintas etapas de su crecimiento, desarrollo y organogénesis. La transmisión in utero de Treponema pallidum origina una diseminación del organismo en el feto, similar a una sífilis secundaria, describiéndose cambios patológicos tan precoces como a las 15 semanas de gestación ${ }^{3}$. Los sistemas y órganos más afectados son el esquelético, cerebro, hígado y pulmón ${ }^{3}$.

Desde fines de los años 80 se ha comunicado un incremento en los casos de sífilis, lo que ha traído como consecuencia un aumento en la incidencia de sífilis congénita. La Organización Mundial de la Salud (OMS) estima que 12 millones de personas son infectadas con sífilis cada año y más de $90 \%$ de las infecciones ocurren en países en desarrollo ${ }^{4}$. La sífilis congénita es un problema relevante asociado a embarazos no controlados o infecciones tardías y refleja el comportamiento de la sífilis en general ${ }^{5}$. Ésta puede ocasionar: muerte fetal con aborto espontáneo o mortinato ( 30 a 40\% de los casos), parto prematuro, recién nacidos de término con signos de infección o asintomáticos; esta última condición se observa en aproximadamente dos tercios de los $\operatorname{casos}^{6}$. Estos son los motivos fundamentales para la prevención, vigilancia y control de esta patología, como también de otras infecciones de transmisión sexual (ITS).

La sífilis congénita puede ser similar en su forma de presentación a diversas infecciones congénitas, patologías por incompatibilidad sanguínea u otras condiciones neonatales. Además en ciertas ocasiones su diagnóstico suele ser difícil, ya que puede presentarse en forma similar a una sepsis bacteriana neonatal, la que sin un diagnóstico precoz y adecuada terapia antibacteriana puede ocasionar secuelas irreversibles o la muerte del paciente.

Comunicamos el caso de una recién nacida de cuatro semanas de vida, con antecedente de embarazo controlado, sin diagnóstico en el período neonatal inmediato, la cual presentó un shock séptico, resultando ser la manifestación de una sífilis congénita.

\section{Caso clínico}

Recién nacida de 27 días de vida, sexo femenino, sana. Hija de madre de 34 años con adecuado control prenatal. Parto eutócico. RNT 37 sem, AEG, PN 2.900 g, Apgar 
9-9, sin otros antecedentes perinatales. La madre consultó por lesiones cutáneas en las zonas perioral y perianal de cinco días de evolución. El día previo a su internación se objetivó fiebre $\left(39^{\circ} \mathrm{C}\right)$ y compromiso del estado general progresivo. Ingresó a la UCI en regulares condiciones, hiporeactiva, peso de $3.100 \mathrm{~g}$, temperatura axilar 36,5 ${ }^{\circ} \mathrm{C}$, frecuencia cardíaca 162 latidos/min, presión arterial 89/44 mm Hg (PAM 67 mm Hg), frecuencia respiratoria $48 /$ min y saturación de oxígeno de $94 \%$ con oxígeno ambiental. Al examen físico destacaban lesiones eritematosas descamativas palmo-plantares (Figura 1) y en el pabellón auricular derecho además de fisuras en la región peribucal (Figura 2). Abdomen distendido con hepatomegalia de 5 cm bajo el reborde costal y esplenomegalia de $3 \mathrm{~cm}$, sin otros hallazgos.

En los exámenes de laboratorio destacaba: anemia (hematocrito $30 \%)$, leucocitosis $\left(23.100 / \mathrm{mm}^{3}\right)$ y trombocitopenia $\left(110.000 / \mathrm{mm}^{3}\right)$. Proteína C reactiva (PCR) 183 $\mathrm{mg} / \mathrm{L}$, albuminemia 2,4 g/l, GOT $71 \mathrm{U} / \mathrm{L}$, GPT $15 \mathrm{U} / \mathrm{L}$ fosfatasa alcalina $426 \mathrm{U} / \mathrm{L}$, bilirrubinemia $1,3 \mathrm{mg} / \mathrm{dl}, \mathrm{LDH}$ 324 U/L. Sedimento de orina normal y citoquímico de LCR normal ( 5 céls $/ \mathrm{mm}^{3}$, proteinorraquia 43,2 mg/dl). Se planteó el diagnóstico de sepsis de foco cutáneo, iniciándose terapia antibacteriana con cefotaxima y cloxacilina previa toma de cultivos (sangre, orina y LCR). La ecografía abdominal confirmó una hepato-esplenomegalia.

Evolucionó con un shock séptico, requiriendo fluidos de reanimación (40 ml/kg en $1 / 2$ h) y transfusión de eritrocitos $(15 \mathrm{ml} / \mathrm{kg})$, sin necesidad de uso de aminas vasoactivas. Durante el primer día de evolución presentó un ascenso del recuento leucocitario a $45.800 / \mathrm{mm}^{3}$ (linfocitos $59 \%$, monocitos $15 \%$ ), descenso de plaquetas a $73.000 /$ $\mathrm{mm}^{3}$, hipoalbuminemia grave en $1,3 \mathrm{~g} / 1 \mathrm{y}$ acidosis metabólica; orina completa sin proteinuria. Los hemocultivos, urocultivo y cultivo de LCR fueron negativos.

Por las alteraciones hematológicas descritas se realizó estudio virológico para VIH, citomegalovirus, virus de Epstein Barr y parvovirus que resultaron negativos. Además se descartó patología mieloproliferativa. A las 48 h de evolución, se realizó examen de RPR (Rapid plasma reagin) resultando reactivo, por lo que se solicitó VDRL que fue positivo a títulos de 1:128 y VDRL en LCR fue positivo a títulos 1:8 por lo que se confirmó el diagnóstico de sífilis congénita. Las lesiones cutáneas eran compatibles con pénfigo sifilítico y rágades.

Recibió tratamiento con penicilina G sódica 250.000 UI/kg/día i.v cada $6 \mathrm{~h}$ por 21 días, sin presentar complicaciones derivadas de su uso. Se realizó estudio con radiografía de huesos largos la cual mostró una banda hiperlúcida metafisiaria, la TAC cerebral fue normal y el fondo de ojo no evidenció retinitis; la evaluación otorrinolaringológica fue normal.

La paciente presentó una buena respuesta clínica, con mejoría del compromiso hematológico, cutáneo y regre-

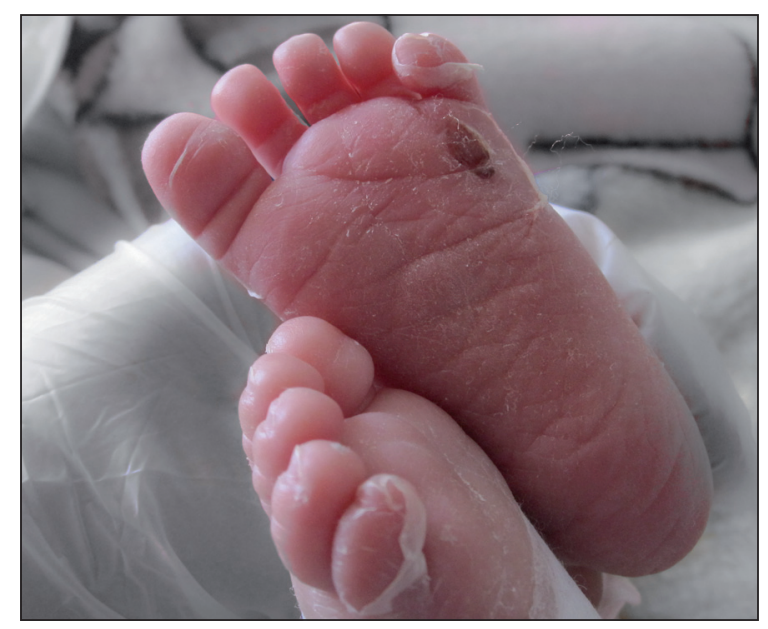

Figura 1. Lesiones descamativas palmo-plantares.

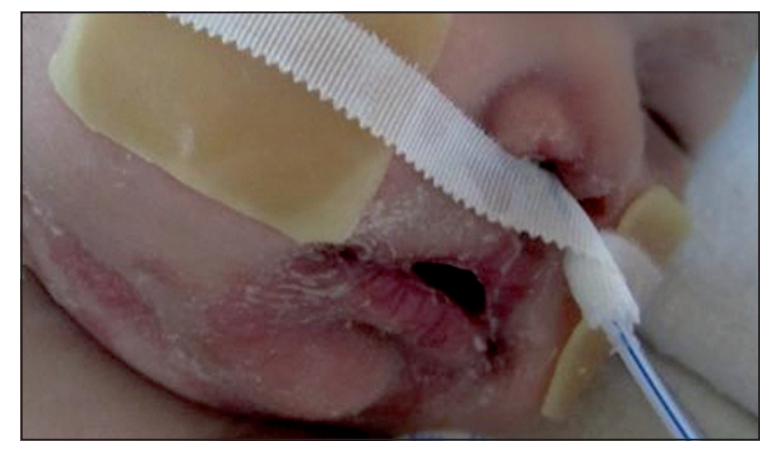

Figura 2. Fisuras en la región peribucal.

sión de la visceromegalia. Fue dada de alta de la UCI a los 13 días de evolución y del hospital al mes de ingresada.

A las 7 semanas desde el alta presentó un descenso de los títulos de VDRL (1:32) y a los cinco meses se objetivó VDRL en sangre y LCR negativos. En el seguimiento a los doce meses la paciente no evidenció secuelas.

Al revisar los antecedentes clínicos maternos se confirmó un VDRL no reactivo en dos oportunidades $\left(1^{\circ}\right.$ y $2^{\circ}$ trimestre del embarazo) y un RPR al momento del parto no reactivo. Se efectuó VDRL materno el cual resultó positivo a títulos 1:32 y serología para VIH negativa. Se derivó a ambos padres a tratamiento por ITS.

\section{Discusión}

La sífilis congénita ocurre en la mayoría de los casos cuando T. pallidum cruza la placenta durante el embarazo (vía transplacentaria) de una madre infectada (no tratada o inadecuadamente tratada) o por contacto con una lesión genital infectada al momento del parto ${ }^{7}$. La infección in utero puede ocurrir en cualquier trimestre del embarazo, incluso tan precozmente como a las 9-10 semanas de 
gestación ${ }^{3}$.

Según la ley de Kassowitz, el riesgo de transmisión vertical de sífilis en mujeres no tratadas disminuye en la medida que la enfermedad materna progresa, con una transmisión vertical de 70 a $100 \%$ para sífilis primaria, $67 \%$ para sífilis secundaria, 40 a $83 \%$ para sífilis latente precoz y $10 \%$ para sífilis latente tardía ${ }^{8,9}$

Estimaciones de la OMS señalan que entre 715.000 a 1.575.000 mujeres embarazadas son infectadas con sífilis anualmente ${ }^{10}$. A consecuencia de esto, cada año 500.000 neonatos nacen con sífilis congénita y otro medio millón de embarazos termina en mortinatos o abortos, ocurriendo la mayoría de los casos en países con recursos limitados ${ }^{11}$. Sin embargo, en la última década la sífilis congénita ha resurgido en países industrializados como E.U.A, donde la tasa aumentó en 23\% durante el período 2005-2008, después de un incremento de $38 \%$ en la tasa de sífilis en mujeres y niñas de este país durante el período 2004$2007^{12}$. Estas cifras estadísticas son más elevadas que para otras infecciones neonatales incluyendo la infección por VIH y tétanos ${ }^{13}$.

En Chile, desde el año 1992 se ha registrado una disminución sostenida de la sífilis (de 38,3 por 100.000 habitantes a 14,2 por 100.000 habitantes en 2010). Sin embargo, en mujeres embarazadas, entre 2001 y 2007 , el número de casos presentó un aumento de $420 \%$, mientras que la sífilis congénita en igual período se ha visto incrementada en $132 \%$ a pesar de los altos indicadores de control de embarazo y atención profesional del parto en nuestro país. Del total de casos de sífilis, alrededor de $0,2 \%$ corresponden a casos de sífilis congénita ${ }^{14}$. Según información del sistema de Enfermedades de Notificación Obligatoria (ENO) hasta la semana epidemiológica $50 \mathrm{del}$ año 2011, se habían notificado 3.548 casos, alcanzando una tasa de incidencia de 20,6 por cien mil habitantes. El grupo etario en edad fértil (15 a 49 años) representa $81 \%$ de los casos y la sífilis congénita concentra $1,4 \%{ }^{15}$.

Similar a la clasificación de la sífilis en población adulta, la sífilis congénita puede presentarse en estadios: precoz, cuando las manifestaciones clínicas se presentan en los dos primeros años de vida y tardía cuando los síntomas ocurren después de esta edad ${ }^{10}$. La forma precoz es el resultado de la diseminación hematógena de las espiroquetas y habitualmente se presenta durante el período neonatal y rara vez después de los 3 a 4 meses de vida. Se estima que más de $60 \%$ de los niños infectados son asintomáticos al momento del parto ${ }^{16}$, manifestándose los síntomas de la enfermedad, en dos tercios de los casos, entre las 3 y 8 semanas de edad.

Una vez ocurrida la infección del feto, cualquier órgano puede verse comprometido. En tres series clínicas de 139 niños con sífilis congénita sintomática los hallazgos más comunes fueron: hepato-esplenomegalia (71\%), exantema $(68 \%)$, fiebre $(42 \%)$, neurosífilis $(23 \%)$ y neumonitis
(17\%). Entre las alteraciones de laboratorio destacaban cambios óseos en la radiografía como periostitis u osteocondritis $(78 \%)$, leucocitosis $(72 \%)$, anemia $(58 \%)$, trombocitopenia (40\%) y compromiso renal (hematuria, proteinuria) $(16 \%)^{17-19}$.

El compromiso hepático es una de las manifestaciones más precoces y puede ser parte de un síndrome séptico o presentarse en forma aislada ${ }^{20}$. La hepato-esplenomegalia e ictericia son los hallazgos más frecuentes en el examen físico durante el período neonatal ${ }^{21}$.

Las manifestaciones muco-cutáneas de la sífilis congénita ocurren hasta en $70 \%$ de los pacientes y pueden estar presentes al momento del nacimiento o desarrollarse durante las primeras semanas de vida $^{3}$, como en el caso aquí comunicado. La erupción cutánea típica consiste en lesiones eritematosas máculo-papulares pequeñas (similares a las lesiones de sífilis secundaria), afectando usualmente plantas, palmas, nalgas, muslos y zona perioral ${ }^{22}$. Pueden observarse fisuras alrededor de labios, narinas o región anal. Otras manifestaciones muco-cutáneas han sido reportadas, incluyendo lesiones vesículo-bulosas ${ }^{23}$, condilomas lata ${ }^{24}$, lesiones anulares ${ }^{25}$ y similares a los del eritema multiforme ${ }^{26}$. Existe una variante de las lesiones bulosas denominada pénfigo sifilítico y ocurre principalmente en palmas y plantas, pero también puede ser generalizado ${ }^{27}$. El compromiso de la mucosa nasal se manifiesta por estornudos (rinitis sifilítica), la cual aparece después de la primera semana de vida. La rinorrea a veces puede ser sanguinolenta; cuando esta es purulenta puede indicar sobreinfección bacteriana ${ }^{3}$. Todas las lesiones muco-cutáneas contienen gran cantidad de espiroquetas y son altamente contagiosas.

Las alteraciones hematológicas también son comunes, pero ocurren tardíamente. La anemia está presente en la mayoría de los neonatos con sífilis congénita y la trombocitopenia es habitualmente leve. El recuento leucocitario puede presentar valores variables, con frecuente hallazgo de monocitosis. El desarrollo de hidrops fetal ocasionado por anemia no hemolítica es altamente sugerente de etiología sifilítica.

La forma tardía está caracterizada por la presencia de lesiones óseas, corneales (queratitis intersticial) y del sistema nervioso central (convulsiones, tabes dorsal) ${ }^{28}$. Muchas de estas lesiones no son reversibles con la terapia antibacteriana pues son lesiones destructivas residuales de la etapa precoz ${ }^{3}$.

La presentación de la sífilis congénita como cuadro séptico posterior al período neonatal inmediato es infrecuente, con alta mortalidad en ausencia de tratamiento.

En la revisión de la literatura científica, los reportes referentes a esta forma de presentación de la sífilis congénita son escasos. En 1990, Dorfman y cols. ${ }^{29}$, comunicaron siete casos de sífilis congénita sintomática que se presentaron después de la tercera semana de vida 
(rango de edad: 3 a 14 semanas). Tres casos se presentaron con fiebre y ausencia de síntomas clásicos. Las manifestaciones clínicas fueron compatibles con sepsis y compromiso multisistémico. Lago y cols. ${ }^{20}$, reportaron un paciente de 40 días de vida que presentó fiebre, hepatoesplenomegalia y compromiso hematológico grave. Se diagnosticó sífilis al quinto día de hospitalización. Sarig y cols ${ }^{30}$ comunicaron el caso de un paciente de seis semanas de edad que evolucionó con sepsis asociada a disfunción hematológica: coagulación intravascular diseminada (CID). Recientemente Grover y cols. ${ }^{31}$, reportaron el segundo caso de CID neonatal ocasionada por sífilis congénita complicada con el desarrollo de un hematoma intracraneal. Otra complicación descrita y similar en su forma de presentación a la sepsis, fue comunicada por Pohl y cols. ${ }^{32}$, donde un paciente de cinco semanas de edad, sin diagnóstico previo, desarrolló un síndrome hemofagocítico con pancitopenia grave, evolucionando con hepato-esplenomegalia rápidamente progresiva y shock; luego de dos meses hubo normalización de los parámetros hematológicos. Se sugiere que en pacientes con infección por $T$. pallidum y que evolucionen con síndrome de disfunción orgánica múltiple (SDOM), debe plantearse como diagnóstico diferencial la linfohistiocitosis hemofagocítica, como en el caso publicado por Bennett y cols ${ }^{33}$.

En el presente caso, además de la presentación inusual, destacó los niveles elevados de PCR, lo que hizo presumir inicialmente una etiología bacteriana de la sepsis. En relación a este hallazgo, Meneghello y cols. ${ }^{34}$, en una de las casuísticas nacionales más importantes de sífilis congénita a mediados del siglo pasado, refirieron como un aspecto de interés la existencia de sedimentación globular elevada en 30 de 33 pacientes. Dos años más tarde, Rosselot y cols. $^{35}$, en una serie de 57 pacientes, establecieron una relación estrecha entre valores de sedimentación globular elevada y alteraciones óseas.

El diagnóstico de sífilis congénita es difícil de establecer, ya que T. pallidum no puede ser cultivado desde los sitios de infección. Actualmente no se dispone de un método rápido, sensible y específico que confirme el diagnóstico en los recién nacidos, principalmente en aquellos que nacen asintómaticos. La utilización del test de "infectividad" en conejos es el estándar para realizar el diagnóstico; sin embargo, es lento y costoso, por lo que se realiza sólo en laboratorios de investigación ${ }^{36,37}$. La detección de espiroquetas en muestras de fluidos por microscopia de campo oscuro es de baja sensibilidad en los recién nacidos ${ }^{38}$, por la escasa concentración del microorganismo. Por esto el diagnóstico de sífilis congénita se basa en los hallazgos del examen físico y en los resultados de las pruebas serológicas.

Los ensayos serológicos utilizados, tanto los no treponémicos (VDRL y RPR) como los treponémicos: fluorescent treponemal antibody absorption (FTA-ABS) y microhemagglutination test for antibodies to Treponema pallidum (MHA-Tp) detectan IgM e IgG. Las pruebas no treponémicas muestran la reactividad hacia antígenos de cardiolipina-lecitina-colesterol, para reconocer posibles anticuerpos contra T. pallidum y reflejan la actividad de la enfermedad. Es criterio diagnóstico de sífilis congénita un aumento de los títulos séricos, al menos, cuatro veces mayor que los títulos maternos ${ }^{17,39}$. Estos resultados son sugerentes, pero no son el único marcador utilizado para el diagnóstico. Su sensibilidad estimada es de 4-13\% ${ }^{40,41}$ y especificidad de $99 \%{ }^{41}$. Hay que considerar que sólo en $22 \%$ de los niños infectados intra-útero los títulos de las pruebas no treponémicas son superiores a los de la madre ${ }^{42}$, por ello la relación de títulos séricos paciente/ madre menor a cuatro veces no excluye el diagnóstico de infección congénita ${ }^{3}$.

Las pruebas treponémicas detectan específicamente anticuerpos contra T. pallidum (IgA, $\operatorname{IgM}$ e $\operatorname{IgG}$ ), pero no diferencian entre otros treponemas. Durante el embarazo, especialmente en el último trimestre, se produce paso de IgG por la placenta, de forma que una serología positiva en el neonato no nos permite diferenciar entre el traspaso pasivo de anticuerpos maternos y la infección del mismo ${ }^{38}$, por lo cual la interpretación de sus resultados es complicada y no se utiliza como criterio diagnóstico.

Considerando que los anticuerpos IgM maternos no cruzan la placenta, si éstos están presentes en el suero del neonato podría ser considerado como evidencia de infección congénita ${ }^{43}$. Se han desarrollado diversas tecnologías para la detección de anticuerpos IgM pero han mostrado una baja sensibilidad en niños asintomáticos. Estas pruebas requieren una técnica compleja y no se las utiliza de rutina. Entre ellas se pueden mencionar: IgM FTA-Abs 19s, IgM de captura por ELISA (CAPTIA $\left.{ }^{\circledR}\right)$ y Western Blot ${ }^{3,10,43}$

El Centro de Control y Prevención de Enfermedades (CDC), de Atlanta, Georgia, sugiere que los test serológicos deben ser realizados en suero materno, ya que en el suero del neonato podrían ser no reactivos si la serología materna resulta en títulos bajos o si la madre se infectó tardíamente durante el embarazo. Asimismo la realización de las pruebas serológicas en sangre de cordón no está recomendada ya que puede ser contaminada por sangre materna y dar resultados falsamente positivos ${ }^{44}$. Numerosos estudios han analizado la sensibilidad, especificidad y valores predictores positivos y negativos de las pruebas no treponémicas, realizadas en muestras de suero materno y sangre de cordón, coincidiendo que ambas tienen altas tasas de falsos positivos. Abarzúa y cols. ${ }^{45}$, publicaron que el suero materno presentó $53 \%$ de falsos positivos y la muestra de cordón, $65 \%$. Sin embargo, los estudios también coinciden en que la tasa de falsos negativos es diferente según el tipo de muestra analizada, siendo más 
alta en muestra de cordón que en suero materno ( $5 \mathrm{vs}$ $0,5 \%$ ), pudiendo no pesquisar casos de sífilis materna y sífilis congénita si sólo se toma muestra de cordón ${ }^{45}$. La actual normativa del MINSAL indica realizar cuatro tamizajes a las mujeres embarazadas: al primer control, a las 24 semanas, entre las 32 y 34 semanas y al momento de ingresar al parto ${ }^{46}$.

El uso clínico de RPC en líquido amniótico, sangre o LCR, es un método alternativo con buena sensibilidad $(78-86 \%)$ y especificidad $(100 \%)^{43}$. Yamamoto y cols. ${ }^{47}$, enfatizan su utilidad en el inicio de la terapia, dado el gran porcentaje de pacientes asintomáticos al momento del diagnóstico, además de permitir la identificación de la espiroqueta en diferentes medios.

En el caso aquí comunicado, la falsa negatividad de las pruebas no treponémicas maternas puede explicarse por la adquisición, en forma tardía, de la infección durante el embarazo. Treponema pallidum invade la circulación después de la inoculación muco-cutánea, pero la reactividad de estos ensayos ocurre 4 a 8 semanas después de adquirida la enfermedad ${ }^{48,49}$. Asimismo, se describe que una determinación serológica puede ser falsamente negativa por una elevada concentración de anticuerpos que inhiben la aglutinación, hecho denominado fenómeno de prozona ${ }^{3}$.

En conclusión, el correcto diagnóstico de sífilis congénita es difícil de establecer por la historia materna y sintomatología ya que esta última es similar a otras infecciones congénitas, como también a la sepsis bacteriana, por lo que hay que considerarla como diagnóstico diferencial de patologías con alteraciones hematológicas y compromiso cutáneo. Nuestra paciente presentó síntomas clínicos sugerentes de sífilis (compromiso mucocutáneo sífilimorfo, hepato-esplenomegalia y alteraciones hematológicas); no obstante, inicialmente estas no fueron valoradas correctamente, atribuyéndose a otras causas como sepsis bacteriana o leucemia congénita, probablemente por la ausencia de historia materna alusiva a esta patología, ya que hubo un adecuado control del embarazo como también exámenes de pesquisa diagnóstica negativos.

Se debe mantener un alto índice de sospecha y familiaridad con la presentación clínica y complicaciones, ya que la sífilis congénita puede ser tratada exitosamente, constituyéndose en una enfermedad potencialmente erradicable; no obstante, sigue siendo un problema de salud vigente, particularmente en países en desarrollo.

\section{Resumen}

El espectro clínico de la sífilis congénita varía desde la infección asintomática a una sepsis fulminante. Comunicamos el caso de un recién nacido de sexo femenino, de 27 días de edad, sano, sin antecedentes maternos, con adecuado control obstétrico y screening prenatal negativo. Consultó por fiebre y lesiones cutáneas de 24 $\mathrm{h}$ de evolución. Ingresó a unidad de cuidados intensivos con compromiso sensorial, hiporeactividad, con lesiones descamativas eritematosas peribucales, palmo-plantares y hepato-esplenomegalia. En los exámenes de laboratorio destacó la presencia de anemia, leucocitosis, trombocitopenia y PCR elevada. Evolucionó con shock séptico, hipoalbuminemia y acidosis metabólica. Se diagnosticó sífilis congénita por VDRL con títulos 1:128 y VDRL en LCR con títulos 1:8; el VDRL materno fue 1:32. Completó terapia con penicilina $\mathrm{G}$ i.v. por tres semanas con adecuada respuesta clínica y de laboratorio. La sífilis congénita puede no ser diagnosticada al momento del nacimiento, por ende se debe tener un alto índice de sospecha, considerando los posibles errores en la serología prenatal y las variadas formas de presentación clínica, incluida la sepsis neonatal, durante el primer mes de vida.

\section{Referencias bibliográficas}

1.- Spence J M. Gonococcia. Clin Obstet Ginecol 1983; 1: 129-31.

2.- Medivisión. Historia de las enfermedades: sífilis y gonorrea. Disponible en: http://www. revistamedica. $8 \mathrm{~m} . \mathrm{com} /$ histomed11A.htm. (Accedido 27 de diciembre de 2011).

3.- Woods C R. Syphilis in children: congenital and acquired. Semin Pediatr Infect Dis 2005; 16: 245-57.

4.- World Health Organization. Global prevalence and incidence of curable sexually transmitted infections. Overview and estimates. Geneva: World Health Organization; 2001: 1-42.

5.- Hook E W 3rd, Peeling R W. Syphilis control-a continuing challenge. N Engl J Med 2004; 351: $122-4$.
6.- Jensen H B. Congenital syphilis. Semin Pediatr Infect Dis 1999; 10: 183-94.

7.- Chakraborty R, Luck S. Managing congenital syphilis again? The more things change. Curr Opin Infect Dis 2007; 20: 247-52.

8.- Hollier L M, Harstad T W, Sánchez P J, Twickler D M, Wendel G D Jr. Fetal syphilis: clinical and laboratory characteristics. Obstet Gynecol 2001; 97: 947-53.

9.- Singh A E, Romanowski B. Syphilis: review with emphasis on clinical, epidemiologic, and some biologic features. Clin Microbiol Rev 1999; 12: 187-209.

10.- Woods C R. Congenital syphilis-persisting pestilence. Pediatr Infect Dis J 2009; 28: 536-7.

11.- World Health Organization The global elimination of congenital syphilis: rationale and strategy for action. Geneva: World Health Organization; 2007: 1-38.

12.- Centers for Disease Control and Prevention Congenital syphilis-United States, 2003-2008. MMWR Morb Mortal Wkly Rep. 2010; 59: 413-7.

13.- Oletta J F, Carvajal A C. Sífilis congénita: Un problema de salud continuo pero descuidado. Red de Sociedades Científicas Médicas de Venezuela. Noticias Epidemiológicas 2010; 24: 1-25. Disponible en http://www.aipop.org/site uploads/be4bf79f-54d2-78a3.pdf (Accedido 20 de mayo de 2012).

14.- Santander C B Fich H, Salvo LA, Pacheco L G, Mendoza M I Garcés I d, et al. Normas de manejo y tratamiento de las Infecciones de Transmisión Sexual (ITS). Primera parte. 
Rev Chilena Infectol 2009; 26: 174-90.

15.- Sifilis. Situación epidemiológica,semanas 1 a 50, año 2011. Disponible en:http://epi.minsal.cl/ epi/html/AtlasInteractivos/AB 100/Sifilis.htm. (Accedido 5 de enero de 2012).

16.- Lewis L L. Congenital syphilis. Serologic diagnosis in the young infant. Infect Dis Clin North Am 1992; 6: 31-9.

17.- Mascola L, Pelosi R, Blount J H, Alexander C E, Cates W Jr. Congenital syphilis revisited. Am J Dis Child 1985; 139: 575-80.

18.- Berry M C, Dajani A S. Resurgence of congenital syphilis. Infect Dis Clin North Am 1992; 6: 19-29.

19.- Wilkinson R H, Heller R M. Congenital syphilis: resurgence of an old problem. Pediatrics 1971; 47: 27-30.

20.- Lago E G, García PC. Congenital syphilis: an emerging emergency also in Brazil J Pediatr (Rio J) 2000; 76: 461-5.

21.- Ingall D, Sánchez P J, Musher D M. Syphilis. In: Remington JS, Klein JO, eds. Infectious Diseases of the Fetus and Newborn Infant. Philadelphia: WB Saunders; 1995. p. 529-64.

22.- Peihong J, Zhiyong L, Rengui C, Jian W. Early congenital syphilis. Int J Dermatol 2001; 40: 198-202.

23.- Vural M, Ilikkan B, Polat E, Demir T, Perk Y. A premature newborn with vesiculobullous skin lesions. Eur J Pediatr 2003; 162: 197-9.

24.- Karthikeyan K, Thappa D M. Early congenital syphilis in the new millennium. Pediatr Dermatol 2002; 19: 275-6.

25.- Agarwal U S, Malpani S, Mathur N K. Annular lesions in congenital syphilis. Genitourin Med 1992; 68: 195-6.

26.- Wu C C, Tsai C N, Wong W R, Hong H S, Chuang Y H. Early congenital syphilis and erythema multiforme-like bullous targetoid lesions in a 1-day-old newborn: detection of Treponema pallidum genomic DNA from the targetoid plaque using nested polymerase chain reaction. J Am Acad Dermatol 2006; 55 (2 Suppl): S11-5.

27.- Kim J K, Choi S R, Lee H J, Kim D H,
Yoon M S, Jo H S. Congenital syphilis presenting with a generalized bullous and pustular eruption in a premature newborn. Ann Dermatol 2011; 23 Suppl 1: S127-30.

28.- Odom R B, James W D, Berger T G. Andrews' diseases of the skin, 9th ed. Philadelphia: W.B. Saunders, 2000, p. 460-4.

29.- Dorfman D H, Glaser J H. Congenital syphilis presenting in infants after the newborn period. N Engl J Med 1990; 323: 1299-302.

30.- Sarig O, Amir J, Tamary H, Volovitz B, Nussinovitch M. Sepsis, disseminated intravascular coagulation (DIC) and hematological aspects as an unusual manifestation of congenital syphilis. Harefuah 2003; 142: 170-2.

31.- Grover S B, Mahato S, Chellani H, Saluja S, Rajalakshmi G P. Disseminated intravascular coagulation with intracranial haematoma in neonatal congenital syphilis. J Trop Pediatr 2011; 57: 315-8.

32.- Pohl M, Niemeyer C M, Hentschel R, Duffner U, Bergsträsser E, Brandis M. Haemophagocytosis in early congenital syphilis. Eur J Pediatr 1999; 158: 553-5.

33.- Bennett M L, Lynn A W, Klein L E, Balkowiec K S. Congenital syphilis: subtle presentation of fulminant disease. J Am Acad Dermatol 1997; 36: 351-4.

34.- Meneghello J, Rosselot J, Niemeyer H. Lúes congénita en el lactante distrófico. Rev Chil Pediatr 1948; 19: 116-20.

35.- Rosselot J, Mardones F. Sedimentación globular en la lúes congénita del lactante. Rev Chil Pediatr 1950; 21: 357-63.

36.- Larsen S, Pope V, Johnson R, Kennedy E. A Manual of Tests for Syphilis. 9th Edition 1998. American Public Health Association, Washington DC. pág 1-361.

37.- Ingall D, Sánchez P J, Baker C J. Chapter 18. Syphilis. En Remington \& Klein, Wilson and Baker. Infectious Diseases of the Fetus and Newborn Infant. JS Remington, JO Klein, Ch B Wilson, CJ Baker, cols. Syxth edition 2006 Elsevier Saunders, Philadelphia, PA, USA. pp 545-80.

38.- Reyes A, Chorbadjian G, Parada M A,
Turrys J, Bravo N, Araya C. Sífilis congénita: Optimizando el diagnóstico en 191 neonatos de madres seropositivas. Rev Chilena Infectol 2004; 21: 307-11.

39.- Zenker P. New case definition for congenital syphilis reporting. Sex Transm Dis 1991; 18: 44-5.

40.- Rawstron S A, Bromberg K. Comparison of maternal and newborn serologic tests for syphilis. Am J Dis Child 1991; 145: 1383-8.

41.- Taber L H, Huber T W. Congenital syphilis. Prog Clin Biol Res 1975; 3: 183-90.

42.- Stoll B J, Lee F K, Larsen S, Hale B Schwartz D, Rice R. et al. Clinical and serologic evaluation of neonates for congenital syphilis: a continuing diagnostic dilemma. J Infect Dis 1993; 167: 1093-9.

43.- Herremans T, Kortbeek L, Notermans D W. A review of diagnostic tests for congenital syphilis in newborns. Eur J Clin Microbiol Infect Dis 2010; 29: 495-501.

44.- Centers for Disease Control and Prevention, Workowski KA, Berman S M. Sexually transmitted disease treatment guidelines, 2006. MMWR Recomm Rep 2006; 55 (RR-11): $1-94$

45.- Abarzúa F, Belmar C, Rioseco A, Parada J, Quiroga T, García P. Pesquisa de sífilis congénita al momento del parto: ¿Suero materno o sangre de cordón? Rev Chilena Infectol 2008; 25: $155-61$.

46.- Ministerio de Salud de Chile. Modificación del texto de la norma general técnica $\mathrm{N}^{\circ} 46$ sobre manejo y tratamiento de enfermedades de transmisión sexual. Resolución exenta $\mathrm{N}^{\circ} 262$, 2006.

47.- Yamamoto M, Lizama L, Valenzuela P, Carrillo J, Insunza A, Prado P. Diagnóstico antenatal de sífilis congénita por PCR en líquido amniótico y sus posibles aplicaciones. Rev Chil Obstet Ginecol 2005; 70: 87-90.

48.- Spangler A S, Jackson J H, Fiumara N J, Warthin T A. Syphilis with negative blood test reaction. JAMA 1964; 189: 87-90.

49.- Felman Y. How useful are the serologic tests for syphilis? Int J Dermatol 1982; 21: 79-81. 